Revista Iberoamericana, Vol. LXXVII, Núms. 236-237, Julio-Diciembre 2011, 771-788

\title{
TEORÍAS SOBRE LA NARRACIÓN: LA PRIMACÍA DE LO HUMANO
}

\author{
POR \\ Mary Fleur Mac-Millan Kuthe \\ Universidad Adolfo Ibañez
}

¿Qué es una narración? En el presente trabajo ${ }^{1}$ revisaremos algunas respuestas a la pregunta por la narración. Nos han interesado pensadores que la conciben como una actividad intrínsecamente humana y portadora de sentido. Así, el estatuto de la narración va más allá de un género literario, ya que se amplía hacia el sentido de lo humano. Por eso, nuestro recorrido incluye tanto una caracterización de tipo más técnica (definiciones, rasgos, etc.), como un marco mayor en el que se abordan distintas concepciones de la narración. Nos basamos primeramente en Paul Ricoeur y Hayden White para luego abrir un diálogo con Hannah Arendt y Primo Levi.

\section{Narración SEgún Paul Ricoeur ${ }^{2}$}

Ricoeur piensa la narración desdeAristóteles y su concepto de trama: "En lanarración, la innovación semántica consiste en la invención de una trama, que también es una obra de síntesis: en virtud de la trama, fines, causas y azares se reúnen en la unidad temporal de una acción total y completa” (Tiempo 1: 33). Toda la lectura de Ricoeur apunta a recalcar la trama como un acto de composición. Es decir, no subyace una estructura en cuanto tal, sino que la trama consiste precisamente en un acto creador mediante el cual se instaura un determinado orden. Tenemos un acto de configurar y una configuración que es la trama misma, la que posee como rasgo básico la concordancia. La concordancia se refiere al rasgo de "totalidad" y la ligazón que debe haber entre principio, medio y fin. Es la trama la que genera la ligazón, más que una lógica propia de los acontecimientos: "si la sucesión puede subordinarse de este modo a alguna conexión lógica, es porque las

1 Este trabajo es parte del proyecto de investigación Fondecyt No 11075019, titulado Constitución de un sujeto sobreviviente en la poesía de Tomás Harris: Trauma, Cuerpo y Narración.

2 Contestaremos a la pregunta por la narración siguiendo algunos postulados de Paul Ricoeur esparcidos a lo largo de los tres tomos de Tiempo y narración (2004). 
ideas de comienzo, de medio y de fin no se toman de la experiencia: no son rasgos de la acción efectiva, sino efectos de la ordenación del poema" (1: 93). El acto de composición debe superar la mera sucesión (uno después del otro) por una verosimilitud entendida como uno causado por otro. Pero esta causalidad será siempre interna o autogenerada por la trama misma. De ahí que para Ricoeur trama puede entenderse como una acción metafórica, en la medida en que es ella misma la que genera su coherencia: "[...] y es precisamente esta síntesis de lo heterogéneo lo que se acerca la narración a la metáfora. En ambos casos, lo nuevo -lo no dicho todavía- lo inédito, surge en el lenguaje” (1: 33). La misma actividad creadora y de reconocimiento de semejanzas que hay en la metáfora hallamos en la actividad narrativa. La concepción de metáfora de Ricoeur se aleja un poco de la clásica correspondencia y se acerca más a la idea moderna: "Pero ¿qué es percibir lo semejante sino instaurar la semejanza misma acercando términos que, 'alejados' al principio, aparecen 'próximos’ de pronto”? (1: 32). Llegamos así a una definición más clara de la narración: "la trama de la narración es comparable a esta asimilación predicativa: ella "toma juntos" e integra en una historia total y completa los acontecimientos múltiples y dispersos, y así esquematiza la significación inteligible que se atribuye a la narración tomada como un todo" (1: 32).

Si la trama es un acto creativo de configuración, ¿qué es lo que se configura? Lo configurado son acciones. En sentido estricto una acción es "lo que alguien hace” (1: 116). Pero este sentido se amplía a una red de relaciones de las que se obtiene su plena significación. Así, entender una acción implica captar su finalidad, motivos y agentes:

Las acciones implican fines, cuya anticipación no se confunde con algún resultado previsto o predicho, sino que compromete a aquel de quien depende la acción. Las acciones, además, remiten a motivos, que explican por qué alguien hace o ha hecho algo, de un modo que distinguimos claramente de aquel por el que un acontecimiento físico conduce a otro acontecimiento físico. Las acciones tienen también agentes, que hacen y pueden hacer cosas que se consideran como obra suya. (1: 116-17)

Es decir, concebir la narración como entramado de “acciones” implica a su vez el reconocer que éstas no existen aisladas sino que se sostienen en una red que básicamente implica contestar a las preguntas: ¿quién?, ¿qué?, ¿por qué?, ¿cómo? y ¿̇con o contra quién? (1: 117). Ahora bien, como ya mencionábamos, una trama debe ser más que una enumeración en serie. Ricoeur insiste en la actividad configuradora. Del acto configurante se originan a su vez dos rasgos esenciales de la trama: su capacidad para ser seguida (followability) y de ser re-narrada. Si efectivamente se ha logrado la configuración -es decir, que las acciones individuales superen su aislamiento y se "tomen juntas"entonces el lector podrá seguir y volver a narrar la historia: "la dimensión configurante transforma la sucesión de los acontecimientos en una totalidad significante, que es el correlato del acto de reunir los acontecimientos y hace que la historia se deje seguir” (1:

Revista Iberoamericana, Vol. LXXVII, Núms. 236-237, Julio-Diciembre 2011, 771-788 ISSN 0034-9631 (Impreso) 
134). Dejarse seguir implica un cierto asentimiento por parte del lector: “comprender la historia es comprender cómo y por qué los sucesivos episodios han llevado a esta conclusión, la cual, lejos de ser previsible, debe ser, en último análisis, aceptable, como congruente con los episodios reunidos" (1: 134). La segunda característica que se desprende de la configuración, la de "narrar de nuevo", está ligada al cierre de la historia y su aceptabilidad por parte del lector:

\footnotetext{
Hemos hablado antes del 'punto final' como aquel desde el que puede verse la historia como una totalidad. Podemos añadir ahora que esta función estructural de cierre puede discernirse, más que en el acto de narrar, en el de 'narrar de nuevo' [...], seguir la historia es no tanto incluir las sorpresas o los descubrimientos en el reconocimiento del sentido atribuido a la historia, tomada como un todo, como aprehender los propios episodios bien conocidos como conduciendo a su fin. (1: 135)
}

A lo largo de la exposición de Ricoeur nos solemos topar con algunas definiciones un tanto tautológicas; tal es el caso de la definición de la narración mediante la capacidad “explicativa” de la misma. Narración y explicación, al igual que en la metáfora, serán sinonimizadas: "una narración que no consigue explicar nada tiene de narración; una narración que explica es una narración pura y simple” (249). El atributo de "explicativa” de toda narración surgiría una vez más de su configuración y de los rasgos de followability arriba mencionados. Dicho de otro modo, una narración “explica” precisamente porque es "seguible":

[...] en efecto, proseguir una historia es comprender las acciones, los pensamientos y los sentimientos sucesivos en cuanto presentan una dirección particular. Esto significa que somos impulsados hacia adelante por el desarrollo tan pronto como respondemos a este impulso por las expectativas que conciernen a la conclusión y al resultado de todo el proceso. Vemos ya cómo comprensión y explicación se mezclan inextricablemente en este proceso. (1: 252)

Para Ricoeur toda narración es explicación en la medida en que adviene en su lectura una comprensión tanto del "por qué" como del "qué" (1: 255). Ahora bien, el que la trama sea en sí misma una explicación, insistimos, es un bien que se desprende de la configuración misma, del poner en orden los acontecimientos: "lo que llamamos explicación casi no es más que la forma que tiene la narración de organizarse en una trama comprensible" (1: 285). Cabría aquí preguntarse por lo que deja afuera ese "casi”, pero no nos interesa problematizar de momento con los postulados de Ricoeur.

Recopilemos: la narración es una actividad creativa en la que se logra una "síntesis de lo heterogéneo" (1: 131). La totalidad debe primar por sobre la singularidad de las acciones. De este noción básica se desprenden todos los otros rasgos característicos de

Revista Iberoamericana, Vol. LXXVII, Núms. 236-237, Julio-Diciembre 2011, $771-788$
ISSN 2154-4794 (Electrónico) 
la narración: "ser seguible” (followability), posibilidad de ser re-narrada, aceptación del cierre y portadora de explicación (quién, por qué).

Es importante constatar que la noción de narración descrita es concebida como un paradigma, es decir, como un modelo sobre el cual es factible (y deseable) una serie de modificaciones. Es comprensible una crítica al modelo expuesto como extremadamente "tradicional", sobre todo teniendo en cuenta que en gran medida se basa en nociones aristotélicas (fin, totalidad). Sin embargo, hay que mencionar el juego entre paradigma (tradición) e innovación que Ricoeur mismo expone de la siguiente manera:

Siempre hay lugar para la innovación en la medida en que lo que, en último término se produce, en la poiesis del poema, es siempre una obra singular, esta obra. [...]. Pero lo inverso no es menos verdadero: la innovación sigue siendo una conducta regida por reglas; el trabajo de la imaginación no nace de la nada. Se relaciona, de uno u otro modo, con los paradigmas de la tradición. Pero puede mantener una relación variable con estos paradigmas. El abanico de soluciones es amplio; se despliega entre los dos polos de la aplicación servil y de la desviación calculada, pasando por todos los grados de la ‘deformación regulada’. (1: 138)

Ahora bien, las desviaciones aceptables tienen para Ricoeur un cierto límite, límite que implicará el abandono definitivo del paradigma y por lo tanto de la narración. ¿Cómo se concibe este fin de la narración? Pues precisamente cuando se atente contra la esencia misma de la narración, esto es, el acto configurador propio de la trama. Las variaciones conducirán peligrosamente a un fin de la narración en la medida en que pongan en riesgo el principio formal de la "concordancia-discordancia”. Haciendo hincapié en la totalidad, producto de la ligazón entre comienzo, medio y fin, sostiene: "Es, pues, legítimo tomar como síntoma del fin de la tradición de construcción de la trama el abandono del criterio de la totalidad" (2: 404). Destacamos que a pesar de toda transformación del paradigma, Ricoeur tiende a creer en la permanencia de la narración, así se desprende de la siguiente cita: "Es inimaginable que la narración pueda prescindir de toda configuración, [...] un salto absoluto fuera de cualquier expectativa paradigmática es imposible” (2: 412).

Expondremos a continuación la relación entre narración e identidad. O dicho de otro modo, de qué manera la narración es productora de un sujeto. Ricoeur acuña el concepto identidad narrativa ${ }^{3}$ y la define como aquella identidad "que el sujeto humano alcanza mediante la función narrativa” (Historia 215). Ricoeur fundamenta el aporte de la narración a la formación de la identidad en la medida en que la liga con la temporalidad. Es decir, el acto de narrar implica identidad ya que en él encontramos la

3 Esta vez además de Historia y narración (2004), nos basamos en Sí mismo como otro (1996) e Historia y narratividad (1999).

Revista Iberoamericana, Vol. LXXVII, Núms. 236-237, Julio-Diciembre 2011, 771-788 ISSN 0034-9631 (Impreso) ISSN 2154-4794 (Electrónico) 
dimensión temporal de la experiencia humana: "El relato es la dimensión lingüística que proporcionamos a la dimensión temporal de la vida” (216). La temporalidad es una estructura de la existencia y ésta accede al lenguaje mediante la narratividad. Así se cierra un círculo: la temporalidad le compete a la experiencia humana y ésta a la narración que a su vez es una estructura del lenguaje. Ricoeur entenderá "narración" de un modo abarcador y supra genérico, ya que su intento consiste en presentar una estructura común tanto de la narración histórica como la de ficción. Ahora bien, esta identidad producto de la narración no es una adquisición que realiza un sujeto aislado, sino que se extiende a toda una comunidad: "el frágil vástago, fruto de la unión de la historia y de la ficción, es la asignación a un individuo o a una comunidad de una identidad específica que podemos llamar su identidad narrativa” (Tiempo 3: 997). Es más, la identidad presupone la integración de narraciones previas, armándose así una pertenencia de relatos que se entretejen: "la historia de una vida se constituye por una sucesión de rectificaciones aplicadas a relatos previos, de la misma forma que la historia de un pueblo [...] procede de la serie de correcciones” (3: 999). ¿Cómo se produce, mediante la narración, la identidad? Para Ricouer decir identidad es responder a la pregunta: ¿Quién ha hecho esta acción? Para responder al ¿quién?, necesariamente habrá que contar una vida. Al contar se ponen en marcha todos los procesos ya explicados para la trama: “¿no consideramos las vidas humanas más legibles cuando son interpretadas en función de las historias que la gente cuenta a propósito de ellas?: ¿Y esas historias de vida no se hacen a su vez más inteligibles cuando se les aplican modelos narrativos?” (Sí mismo 107). De la actividad de contar emerge una cierta "legilibilidad" en la que el sujeto aparece o se muestra precisamente como un sujeto dotado de sentido.

Ahora bien, Ricoeur distingue entre identidad como idem (mismidad) y como ipse (sí mismo, self, Selbst). Será importante aclarar esta distinción para situar más exactamente la función de la narración. La identidad como idem (idéntico, Gleich, same) se entiende como inmutable y no cambia a lo largo del tiempo. La identidad como ipse admite el cambio y la diversidad que el sujeto sufre en el paso del tiempo. El idem se vincula a la pregunta ¿qué?, precisamente como si el sujeto fuera un cúmulo de rasgos o características. Le es propio al idem la noción de carácter, el que es invariable a lo largo del tiempo: "designa un conjunto de disposiciones duraderas en las que reconocemos a una persona” (Sí mismo 115). Ahora bien, a este sujeto como un qué, Ricouer contrapone el ipse que es un sujeto entendido como un quién, es decir, alguien que realiza acciones y que se proyecta mediante ellas. Volviendo ahora a la noción de identidad narrativa, en ella encontramos tanto el idem como el ipse, es decir, un sujeto como carácter (rasgos estables) y además desenvuelto en sus acciones: "no nos asombrará ver a la identidad narrativa oscilar entre dos límites, un límite inferior, donde la permanencia en el tiempo expresa la confusión del idem y del ipse, y un límite superior, en el que el ipse plantea la cuestión de su identidad sin la ayuda y el apoyo del idem” (120).

\footnotetext{
\begin{tabular}{l} 
Revista Iberoamericana, Vol. LXXVII, Núms. 236-237, Julio-Diciembre 2011, $771-788$ \\
\hline ISSN 0034-9631 (Impreso)
\end{tabular}
} 
Dicho esto, ¿¿cuál es el papel de la narración en esta identidad entendida como juego entre ipse (quién) e idem (qué)? Recordemos primeramente la cualidad central de la trama, es decir, su "concordancia discordante". En toda trama hay "concordancia" entendida como "un principio de orden que vela por lo que Aristóteles llama 'disposición de los hechos' y simultáneamente hay 'discordancia' entendida como 'los trocamientos de fortuna que hacen de la trama una transformación regulada, desde una situación inicial hasta otra terminal"” (Tiempo 139). La trama se convierte en la mediación misma y origina la síntesis de lo heterogéneo. Aquí es donde Ricoeur establece un salto o analogía desde la trama al personaje. Ya que es el personaje (protagonista) el que hace la acción de la trama, es sobre él mismo que recae la concordancia discordante: "la identidad del personaje se comprende trasladando sobre él la operación de construcción de la trama aplicada primero a la acción narrada; el personaje mismo-diremos-es 'puesto en trama'” (Sí mismo 142). Así, sobre la base de un carácter (idem), en la trama lo que prevalece es un alguien que realiza acciones y, a través de ellas, por muy dispares que sean, logra una cierta unidad. O sea, la identidad del personaje se construye en la trama misma. La trama, al integrar la diversidad de acciones al personaje, reduce la disparidad de éstas.

Ricoeur se plantea a continuación, y sobre todo en las narraciones contemporáneas, la posibilidad de un desequilibrio entre los dos polos de la identidad. Es decir, cuando desaparece el idem y nos encontramos con un yo que es mero ipse que se muestra en el cúmulo de sus acciones. En este caso se está frente a una crisis. Es la literatura, precisamente, quien ha llevado a ese extremo las variaciones posibles: "En este sentido, la literatura parece consistir en un vasto laboratorio para experiencias de pensamiento en las que el relato pone a prueba los recursos de variación de la identidad narrativa” (147-48). Ejemplo de esto es El hombre sin atributos, de Musil, en donde el personaje, reducido a un cúmulo de acciones (quién), ha dejado de poseer un idem que lo sostenga (qué) (148). Una vez más, al constatar una pérdida del sujeto, Ricoeur constata simultáneamente la crisis de la narración en su totalidad: "es importante observar que, a medida que el relato se acerca al punto de anulación del personaje, la novela pierde también sus cualidades propiamente narrativas” (149). Concluye: “A la pérdida de identidad del personaje corresponde así la pérdida de configuración del relato y, en particular, una crisis de la clausura del relato"(149). Alcanzado este punto, Ricouer se pregunta por esa ipseidad que ha perdido el soporte de la mismidad. Se debe ahora incorporar un elemento soslayado en la dimensión del sujeto, nos referimos al componente ético. La identidad narrativa, en la medida en que considera tanto el carácter como la permanencia de sí en el actuar, involucra un aspecto ético. El sujeto de sus acciones es a su vez un sujeto que responde por ellas. O más bien dicho, el quién de las acciones, además de responder a la pregunta ¿quién eres?, debe estar listo para contestar a la pregunta ¿dónde estás? Según Ricouer "esta respuesta es: "heme aquí. Respuesta que dice el mantenimiento de sí” (169). La disolución del sujeto en mera ipseidad es la pérdida de su dimensión ética. Llegado a

\footnotetext{
Revista Iberoamericana, Vol. LXXVII, Núms. 236-237, Julio-Diciembre 2011, 771-788
ISSN 2154-4794 (Electrónico)
} 
un límite Ricouer incluso habla de no-sujeto. Ese no-sujeto, privado de la ayuda del idem, es, a pesar de todo, aún un resto de sujeto:

\begin{abstract}
Si el no-sujeto no fuese aún una figura del sujeto, ni siquiera de forma negativa, no nos interesaríamos por ese drama de la disolución y no nos quedaríamos perplejos ante el mismo. Alguien plantea la pregunta. ¿quién soy? Y recibe una respuesta: ‘nada o casi nada'. Pero se trata todavía de una respuesta a la pregunta ¿quién?, aunque se encuentra reducida a su mínima expresión. (Historia 223)
\end{abstract}

Se insiste pues, pese a todo, en la permanencia de un sujeto, incluso bajo la forma negativa: "La frase: 'No soy nada' debe conservar su forma paradójica: en efecto, 'nada' ya no significaría nada si 'nada' no se atribuye a ‘yo'” (223). Así, recalcamos la permanencia del sujeto a pesar de toda dificultad en responder a la pregunta ¿quién soy? Si seguimos bien a Ricoeur, siempre habrá un “yo”, éste nunca se verá por completo anulado.

\title{
2. LA NARRACión SEGÚN HAYden White
}

Si bien los estudios sobre la narración de White se ubican dentro de la problemática mayor de la relación entre discurso narrativo y representación histórica ${ }^{4}$ (de hecho también los de Ricoeur), varios de sus postulados nos resultan valiosos a la hora de emprender una reflexión sobre la narración. Partimos por el presupuesto más importante de White, y es que la narración no es un medio neutral: "es más bien una forma discursiva que supone determinadas opciones ontológicas con implicaciones ideológicas e incluso específicamente políticas" (Contenido 11). White remarca el interés en las dos últimas décadas por la naturaleza de la narración y su función tanto cultural como social (12). El interés brota del hecho de que la narración no sería un simple medio para comunicar determinado contenido, ya sea histórico o de ficción, sino que "posee ya un contenido previo a cualquier materialización en el habla o la escritura” (13).

En su estudio "El valor de la narrativa en la representación de la realidad" (1992) White se pregunta por la "naturaleza” de la narración. Contesta en primera instancia, en diálogo con Roland Barthes, ligándola a la humanidad misma. Estaría en la naturaleza del hombre el narrar o poner en relatos sus experiencias: "Plantear la cuestión de la naturaleza de la narración es suscitar la reflexión sobre la naturaleza misma de la cultura y, posiblemente, incluso sobre la naturaleza de la propia humanidad” (Contenido 17). Tenemos ya una primera definición de narración: "la narrativa es un metacódigo, un

4 Ver El texto histórico como artefacto literario (2003) y El contenido de la forma. Narrativa, discurso y representación histórica (1992), de White.

$\begin{array}{lllll}\text { ISSN 2154-4794 (Electrónico) } & \text { Revista Iberoamericana, Vol. LXXVII, Núms. 236-237, Julio-Diciembre 2011, }\end{array}$ 
universal humano sobre cuya base pueden transmitirse mensajes transculturales acerca de la naturaleza de una realidad común” (17).

Pasemos ahora a los rasgos concretos mediante los cuales White caracteriza a la narración. En esto se parece mucho a los ya mencionados por Ricoeur, pero su exposición es más pedagógica. Su método consiste en decir lo que “no es” una narración, para desde ahí afirmar lo que es. Escoge como ejemplo el género de los anales y se pregunta qué "le falta" a estos para ser narración. No hay que perder de vista aquí nuestra pregunta central: ¿qué es narrar y cuáles son las implicancias de este acto? La importancia de ir comparando a la luz de los anales lo que es y lo que no es una narración, es que así White pone de manifiesto que la narración es "un modo de representar" y que existen otros. En relación a los acontecimientos y su forma, White sentencia: "Los acontecimientos no sólo han de registrarse dentro del marco cronológico en el que sucedieron originariamente sino que además han de narrarse, es decir, revelarse como sucesos dotados de una estructura, un orden de significación que no poseen como mera secuencia” (21). Según White, producto de la estructuración de los acontecimientos advendría una comprensión de los mismos. Que los acontecimientos por sí mismos no constituyen narración se desprende bellamente de la siguiente cita: "los acontecimientos históricos se disponen para la mirada perceptiva como historias que esperan ser narradas" (22). Una narración o relato debe contar con los siguientes atributos: un tema central, un comienzo bien diferenciado, una mitad y un final, una voz narrativa identificable y una conexión necesaria entre un acontecimiento y otro (229). Decíamos que White toma como ejemplo el modelo de los anales para su argumentación, concretamente el texto de los Anales de Saint Gall. En este listado de acontecimientos que tuvieron lugar en la Galia durante los siglos viII, IX y x hay ausencia total de actividad narrativa. ¿Qué le falta a los anales? Primero una explicación; es decir, si se nos informa "Carlos luchó contra los sarracenos”, no se nos dice el por qué. Explicar es decir por qué. Además falta una introducción, el anal citado simplemente comienza con un supuesto título o encabezado. Otra carencia de los anales es la conclusión. Aquí White introduce la diferencia (ya citada por Ricoeur) entre concluir y simplemente terminar. La narrativización exige, a partir de la estructura relacional de los acontecimientos, una conclusión: "si entendemos por trama una estructura de relaciones por los que se dota de significado a los elementos del relato al identificarlos como parte de un todo integrado" (24). Otra carencia de los anales es la ausencia de criterios que rigen la selección de los acontecimientos anotados: "Cada narrativa, por aparentemente 'completa' que sea, se construye sobre la base de un conjunto de acontecimientos que pudieron haber sido incluidos pero se dejaron fuera; esto es así tanto respecto de las narraciones imaginarias como de las realistas” (25). Es decir, los anales carecen de un principio para valorar los acontecimientos, ya que éstos no son todos igualmente significativos. Nos acercamos a la noción más radical de White sobre la narración, a saber, su conexión con lo moral. Lo que le falta a los

\footnotetext{
Revista Iberoamericana, Vol. LXXVII, Núms. 236-237, Julio-Diciembre 2011, 771-788
ISSN 2154-4794 (Electrónico)
} 
anales y que por oposición posee toda narración es: “una noción de centro social por la cual ubicarlos unos respectos de otros y dotarlos de significación ética o moral” (26). ¿Cómo entiende White este componente moral propio de la narración? En este punto el autor sigue algunos postulados de Hegel, recalcando la íntima relación entre ley, historicidad y narratividad (28). Pareciese que nos alejamos de una narración ficticia y que estos postulados se circunscribirían más propiamente a la narración histórica. Mas he aquí que sorprendentemente White declara:

[...] no nos puede sorprender la frecuencia con que la narratividad, bien ficticia o real, presupone la existencia de un sistema legal contra o a favor el cual pudieran producirse los agentes típicos de un relato narrativo. Y esto plantea la sospecha de que la narrativa en general, desde el cuento popular a la novela, desde los anales a la 'historia' plenamente realizada, tiene que ver con temas como la ley, la legalidad, la legitimidad o, más en general, la autoridad. (28)

Para ser más precisos, ¿en qué radicaría el acto moralizador de la narración? Al parecer, el principio estructurador mismo sería moralizante: "Si toda narración [...] dota a los acontecimientos, reales o imaginarios de una significación que no poseen como mera secuencia, parece posible llegar a la conclusión de que toda narrativa histórica tiene como finalidad latente o manifiesta el deseo de moralizar" (29). Para seguir con el ejemplo de los anales, hay en éste una negativa a moralizar. A modo de ejemplo vemos la siguiente yuxtaposición de frases: "Murió el Emperador Enrique; y le sucedió en el trono su hijo Enrique". Para White este estado embrionario de narratividad elude el componente moralizador. En la medida en que la asunción de Enrique conlleva implicancias de orden moral y legal. La carga moral implícita en la narración se conecta íntimamente con el ya mencionado problema de cierre o conclusión. La exigencia de cierre "es una demanda de valorar las secuencias de acontecimientos reales en cuanto a su significación como elementos de un drama moral” (35). Para White debe existir un vínculo entre el inicio y su final, y ese vínculo de alguna manera implica una postura moralizante o "principio moral” (34). Volvemos a argumentaciones un tanto tautológicas al estilo de Ricoeur: la narración es una actividad regida por una estructuración y ésta le estaría dada por el "principio moral", entendiendo por "principio moral" la capacidad de otorgar significado a las acontecimientos aislados. La categoría de "principio moral” parece tener su fundamentación última en los acontecimientos en sí, ya que todo acontecimiento pertenece a un determinado orden de existencia moral: "los acontecimientos realmente registrados en la narrativa parecen ser reales precisamente en la medida en que pertenecen a un orden de existencia moral, igual que obtienen su significación a partir de la posición en ese orden” (37). En el fondo, la naturaleza moralizante de la narración consiste en que ésta es narración de acontecimientos que a su vez se adscriben a un orden moral, entendiendo por orden moral, creo, una normativa

\footnotetext{
Revista Iberoamericana, Vol. LXXVII, Núms. 236-237, Julio-Diciembre 2011, $771-788$
ISSN 0034-9631 (Impreso)
} 
o legalidad o sistema. White insiste en la imposibilidad de concebir una narración sin un fin. ¿Cómo se entiende este fin? Pues como un cambio de un orden moral a otro. Todo fin es en sí moralizante: “¿En qué pudo haber consistido el cierre narrativo más que en el tránsito de un orden moral a otro? Confieso que no puedo concebir otra forma de ‘concluir' una presentación de los acontecimientos” (37). Para White no hay fin en el sentido de un cese de acontecimientos, hecho imposible, sino "fin" en el sentido de un cambio de "significado": "estos acontecimientos sólo pueden parecer cesados cuando se cambia el significado, y se cambia por medios narrativos, de un espacio físico social a otro" (37). Todos los supuestos rasgos antes enumerados para la narración, o como White prefiere nombrar, “narrativización”, se resumen en el "principio moral”. Ésta es la tesis central y arguye también que habría que reflexionar si es válida o no para las narraciones ya no históricas sino de ficción. Mas he aquí que en relación a este punto, es decir, la distinción entre narración de acontecimientos reales y ficticios y el "principio moral”, White ofrece inquietantes reflexiones. La exigencia de estructuración que se le hace al relato proviene no tanto de la realidad, sino precisamente de la imaginación:

¿Se presenta realmente el mundo a la percepción en la forma de relatos bien hechos, con temas centrales, un verdadero comienzo, intermedio y final, y una coherencia que nos permite ver el 'fin' desde el comienzo mismo? ¿O bien se presenta más en la forma que sugieren los anales y la crónica, o como mera secuencia sin comienzo o fin o como secuencia de comienzos que sólo terminan y nunca concluyen? (38)

Cabe preguntarse si la condición moral que White parece imponer a la narración no sería acaso precisamente una imposición bajo el anhelo de la primacía de la significación.

\section{AlgunAS CONCEPCIONES DE LA NARRACIÓN COMO ACTIVIDAD INTRÍNSECAMENTE HUMANA}

A continuación ahondaremos en el rasgo propiamente humano de la narración mediante la exposición de algunos teóricos que defienden esta postura. Veremos tres respuestas que de un modo u otro son compatibles y se entrelazan. Para Ricoeur, autor ya visto, la narración se liga al hombre mediante la noción de tiempo, para Hannah Arendt mediante la noción de acción, y para Primo Levi mediante el testimonio.

\subsection{Paul Ricoeur: tiempo y experiencia}

$\mathrm{Al}$ exponer anteriormente a Ricoeur dejábamos metodológicamente de lado el contexto del cual extraíamos los rasgos mencionados. Dicho contexto es su enorme obra Tiempo y Narración. Hemos de reinsertar, al menos a manera de esbozo, el marco o la problemática desde la cual Ricoeur se aproxima a la narración, ya que lo que ahora nos interesa exponer es precisamente los supuestos a partir de los que ésta se piensa.

Revista Iberoamericana, Vol. LXXVII, Núms. 236-237, Julio-Diciembre 2011, 771-788 
Dos son estos supuestos: el tiempo y la experiencia. Se inicia el primer tomo de la obra citada así: "el tiempo se hace tiempo humano en cuanto se articula de modo narrativo; a su vez, la narración es significativa en la medida en que describe los rasgos de la experiencia temporal” (39). En el primer capítulo se expone, siguiendo a San Agustín, la aporía del tiempo. Muy sintéticamente, esa aporía consistiría en la imposibilidad de darle una cierta coherencia al pasado, presente y futuro. El acto de narrar se presentaría precisamente como una salida, aquí es donde se introduce el concepto de trama ya explicado anteriormente. La narración se concibe como la mediación que posibilita el acceder a una experiencia unitaria (concordante) del tiempo: "veo en las tramas que inventamos el medio privilegiado por el que re-configuramos nuestra experiencia temporal confusa, informe y, en el límite, muda” (34). Ricoeur va incluso más allá al postular en toda experiencia una estructura pre-narrativa (144), toda experiencia “demanda una narración” (144). Esto lo ejemplifica mediante el concepto de "historia no narrada todavía”. Es decir, experiencias que esperan ser narradas para convertirse así en plenas: "¿no somos propensos a ver en tal encadenamiento de episodios de nuestra vida historias 'no narradas todavía', historias que piden ser contadas, historias que ofrecen puntos de anclaje a la narración?” (144). Ahora bien, la importancia de esta "demanda de narración” implícita en toda experiencia humana es que en ella advendría el propio sujeto de la experiencia: “Así, pues, es necesario que las historias narradas ‘emerjan’ de este segundo plano. Con esta emergencia el sujeto implicado emerge también” (145). Frente a la pregunta ¿por qué narramos?, Ricoeur, sin dudar, responde: "Contamos historias porque, al fin y al cabo, las vidas humanas necesitan y merecen contarse"; y añade a continuación: "esta observación adquiere toda su fuerza cuando evocamos la necesidad de salvar la historia de los vencidos y de los perdedores. Toda la historia del sufrimiento clama venganza y pide narración” (145). Visto así, la narración no solamente es una actividad ligada al hombre y mediante la cual el hombre se piensa y se constituye, sino que es un imperativo ético.

\subsection{Hannah Arendt}

Nuevamente se trata de extraer algunas concepciones sobre la narración de un discurso mucho mayor como son las reflexiones acerca de "la condición humana". En el capítulo cinco de La condición humana (2001), Arendt sostiene que el hombre se constituye en cuanto tal mediante la acción ${ }^{5}$ y la palabra: "con palabra y acto nos insertamos en el mundo humano, y esta inserción es como un segundo nacimiento [...] mediante ellos, los hombres se diferencian en vez de ser meramente distintos; son los modos en que los seres humanos se presentan unos a otros, no como objetos físicos, sino

5 Es conocida la tripartición de Arendt en "labor”, “trabajo” y “acción”.

$\begin{array}{lllll}\text { ISSN 2154-4794 (Electrónico) } & \text { Revista Iberoamericana, Vol. LXXVII, Núms. 236-237, Julio-Diciembre 2011, }\end{array}$ 
qua hombres” (200). Importa aquí recalcar la ligazón entre el accionar y su respectiva narración. Primeramente, algunas aclaraciones en relación al accionar. Arendt lo concibe como una toma de iniciativa por parte del hombre mediante la cual algo nuevo es puesto en movimiento (201). Lo nuevo posee el rasgo de lo inesperado mediante el que nos oponemos a las leyes de lo fatídico y de la muerte. La acción, así concebida, exige, necesita de la narración. Es la narración la encargada de portar la acción en cuanto acto y, lo más importante, revela al sujeto de la acción: “sólo se hace pertinente (el sujeto) a través de la palabra hablada en la que se identifica como actor, anunciando lo que hace, lo que ha hecho y lo que intenta hacer" (2003). ${ }^{6}$ El papel que le otorga Arendt a la narración es, pues, el de hacer aparecer al sujeto humano. Es importante la distinción, ya aludida, del sujeto entendido como un "quién” o como un "qué". La noción de sujeto como un "qué" se refiere a un cúmulo de cualidades estables (dotes, talentos, defectos); en cambio, un "quién” es alguien que hace y que dice. Y es en ese hacer y narrar que se revela en cuanto tal. Mediante acción y narración se responde a la pregunta ¿quién eres tú? (202). La insistencia en el quién por sobre el qué, se fundamenta ya que "todas las definiciones son determinaciones o interpretaciones de qué es el hombre, por lo tanto de cualidades que posiblemente puede compartir con otros seres vivos, mientras que su específica diferencia se hallaría en una determinación de qué clase de quién es dicha persona” (205). O sea, cualquier intento por definir al hombre mediante el qué, sería infructuoso, mientras que en el quién se revela su verdadera naturaleza.

Ahora bien, en esta narrar mediante el cual se revela el sujeto cobra suma importancia el narrador. Para Arendt el propio agenteno estaría capacitado para ejecutar esta tarea.Aquí vuelve a aparecer el problema de la coherencia y del “fin” o del cierre. La comprensión plena del accionar sólo se comprendería una vez llegado a su fin:

[...] su pleno significado sólo puede revelarse cuando ha terminado [...] la narración sólo se revela plenamente al narrador, es decir, a la mirada del historiador, que siempre conoce mejor de lo que se trataba que los propios participantes. Aunque las historias son los resultados inevitables de la acción, no es el actor, sino el narrador, quien capta y hace la historia. (215)

Hay aquí, sin duda, una apuesta por la primacía del sentido y la coherencia. Esta coherencia o sentido estaría dado por el principio ordenador del narrador más que por el agente o las mismas acciones. Y más aún, de la totalidad de las narraciones surgiría una especie de suma que vendría siendo una gran narración. Dicho de otro modo, para

6 Hannah Arendt no lo dice expresamente pero lo podemos deducir de su cita: la narración es también el modo de darle cohesión a la difusa experiencia temporal, en la medida en que el sujeto dé cuenta de lo que hace (presente), de lo que "ha hecho" (pasado) y de lo que "intente hacer" (futuro). Los postulados de Arendt resultan consonantes con los de Ricoeur.

Revista Iberoamericana, Vol. LXXVII, Núms. 236-237, Julio-Diciembre 2011, 771-788 
Hannah Arendt la historia misma es una gran narración de acciones: "pero la razón de que toda vida humana cuente su narración y que en último término la historia se convierta en el libro de narraciones de la humanidad [...] radica en que ambas son el resultado de la acción” (208).

\subsection{Primo Levi}

Si bien Primo Levi no es un teórico tal y como lo entendemos como en el caso de Ricoeur, White y Arendt, en su vasta obra de testigo sobreviviente podemos extraer una teoría de la narración. Nos interesa sobremanera concentrar sus postulados ya que se trata de un narrador nato ${ }^{7}$ y enfrentado a los límites de la representación.

$\mathrm{Al}$ inicio de Si esto es un hombre (2006), libro en el que Primo Levi narra los horrores que padeció en el campo de exterminio nazi, antepone a manera de epígrafe un poema de su propia autoría:

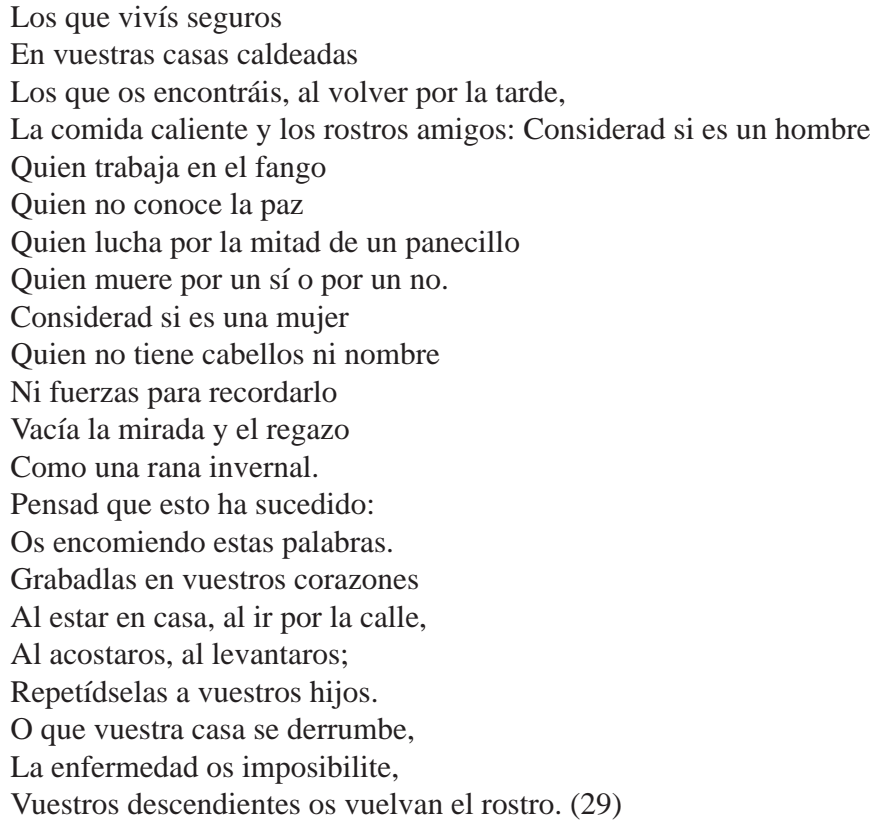

7 De él, Antonio Muñoz Molina, prologador de Trilogía de Auschwitz, afirmará: "narrador en el sentido más primitivo y sagrado, el que cuenta en voz alta y se niega a permanecer en silencio, el depositario y el guardián de una memoria imprescindible” (9).

$\begin{array}{lllll}\text { ISSN 2154-4794 (Electrónico) } & \text { Revista Iberoamericana, Vol. LXXVII, Núms. 236-237, Julio-Diciembre 2011, }\end{array}$ 
Este epígrafe concentra, cual síntesis, algunos de sus postulados acerca de la narración. Primero, toda narración es apelativa y busca su interlocutor. En el poema las expresiones "considerad", "pensad", indican la búsqueda de su lector. Segundo: la palabra (narración) debe ser transmitida e incorporada ("grabadlas en vuestros corazones", "repetídselas a vuestros hijos”). Tercero: la no transmisión de la narración deviene en una maldición. Esta maldición la entendemos como un quiebre con las generaciones posteriores ("vuestros descendientes os vuelvan el rostro"). Cuarto: el contenido mismo de la narración es un saber o cuestionamiento acerca del hombre y de los acontecimientos que lo han llevado a su límite, de ahí precisamente el título: "Si esto es un hombre". El condicional apela ya a un cuestionamiento en el que el lector se hace partícipe y se multiplican las preguntas. ¿Si esto no es un hombre, cómo se ha producido? ¿Por qué? ¿Qué es un hombre? Conocida es la clasificación de Levi de la humanidad en dos grupos: los hundidos y los salvados. ${ }^{8} \mathrm{~A}$ ésta se le añade una segunda, los que callan y los que hablan: "Quienes han experimentado el encarcelamiento (y, mucho más en general, todos los individuos que han pasado por experiencias crueles) se dividen en dos categorías bien diferenciadas, con raros matices intermedios: los que callan y los que hablan” (601). Primo Levi, obviamente, se sitúa en el segundo grupo: es pues, mezclando sus dos tipologías, un salvado que habla. ¿Por qué hablan los sobrevivientes?:

Hablan porque, con distintos niveles de conciencia, reconocen en su prisión, aunque ya lejana, el centro de su vida, el acontecimiento que para bien y para mal ha marcado su existencia entera. Hablan porque saben que han sido testigos de un acontecer de dimensiones planetarias y seculares. Hablan porque (reza un dicho yiddish) 'es bello contar las desdichas pasadas’. (601)

Este imperativo de contar, de poner en una narración una experiencia equis, tiene como principio que le subyace la exigencia de la comunicación. Para Levi, siempre y más allá de toda dificultad, prima y debe primar la esencia del hombre como ser que habla y se comunica: "El término 'incomunicabilidad', tan de moda durante la década de los sesenta, no me ha gustado nunca; en primer lugar porque es una monstruosidad lingüística, y en segundo por razones más personales” (546). Es aquí en donde Levi expresa su más claro y potente postulado:

[...] podemos y debemos comunicarnos: es una manera útil y fácil de contribuir a la paz ajena y a la propia, porque el silencio, la ausencia de señales, es a su vez, una señal,

8 “Queda claro que hay entre los hombres dos categorías particularmente bien distintas: los salvados y los hundidos. Otras parejas de contrarios (los buenos y los malos, los sabios y los tontos, los cobardes y los valientes, los desgraciados y los afortunados) son bastante menos definidas, parecen menos congénitas, y sobre todo admiten gradaciones intermedias más numerosas y complejas” (118).

Revista Iberoamericana, Vol. LXXVII, Núms. 236-237, Julio-Diciembre 2011, 771-788 ISSN 0034-9631 (Impreso) 
pero ambigua, y la ambigüedad genera inquietud y sospechas. Negar la posibilidad de la comunicación es falso: siempre es posible. Rechazar la comunicación es un pecado; para la comunicación, y en especial para su forma altamente evolucionada y noble del lenguaje, estamos biológica y socialmente predispuestos. Todas las razas humanas hablan; ninguna de las especies no humanas sabe hablar. (547)

Ala primacía de la comunicación por sobre el silencio obedece entonces la narración, encargada de transmitir la experiencia límite. Este hecho presupone la existencia de un "otro" que recibe, escucha y comprende la experiencia narrada. Precisamente la tarea del narrador sobreviviente es hacer que ésta llegue a la otra orilla. Levi se cuestiona: " ¿hemos sido capaces los supervivientes de comprender y de hacer comprender nuestra experiencia?”(497).En relación a la primera sentencia, la de la capacidad de comprensión del propio sujeto en relación a su experiencia, Levi afirma la primacía del sentido por sobre el sinsentido: "estoy persuadido de que ninguna experiencia humana carece de sentido ni es indigna de análisis” (117). En el caso concreto de Levi, la experiencia límite es continuada en la del escritor, de sobreviviente se convierte en narrador: "a mi experiencia breve y trágica de deportado se ha superpuesto esa otra mucho más larga y compleja de escritor-testigo" (244). El término "superposición" apunta a esa indisolubilidad entre experiencia y narración, es decir, no es tanto que la experiencia venga primero y luego la narración, sino, en la medida en que la narración es de la experiencia misma, ambas se superponen y se encuentran: escritura y experiencia. En relación a la capacidad de hacer comprensible la experiencia para otro ajeno a ella -ya que aquí radicaría precisamente el valor de la narración, en su poder de transmitir, no ya meros datos, sino una experiencia- Levi recalca la importancia del narrador (historiador) en este proceso. Hay siempre una dificultad no sólo para percibir acontecimientos pasados, sino una "dificultad de percibir las experiencias ajenas [...] tendemos a asimilarlas a las más cercanas, como si el hambre de Auschwitz fuese el de quien se ha saltado una comida” (609). Pues precisamente ese puente insalvable, la radicalidad e incluso irreductibilidad de la experiencia, es posible de ser soslayada gracias a la narración. Las narraciones, o como las llama Levi, historias, van más allá del individuo involucrado, nos involucran a todos y en ella se juega la historia de la humanidad. A veces, y a pesar de lo hostil del medio, los "Häftlinge" se contaban unos a otros sus historias. De un compañero de sufrimiento, Levi afirma:

Me contó su historia, que he olvidado hoy, pero era una historia dolorosa, cruel y conmovedora; porque así son todas nuestras historias, cientos de miles de historias, todas distintas y todas llenas de una trágica y desconcertante fatalidad. Nos las contamos por las noches, y han sucedido en Noruega, en Italia, en Argelia, en Ucrania, y son sencillas e incomprensibles como las historias de la Biblia. ¿Pero acaso no son también historias de una nueva Biblia? (93)

Revista Iberoamericana, Vol. LXXVII, Núms. 236-237, Julio-Diciembre 2011, 771-788 ISSN 0034-9631 (Impreso) 
Esta cita es la afirmación del "contar historias” como elemento inherente a todo ser humano, sin importar origen ni lengua, la primacía de la narración aun en medio de la locura y el sinsentido del campo de concentración. Y más aún, es la narración como un tejido de múltiples voces que conforman entre sí la historia misma. Toda experiencia, en la medida en que encierra un secreto (lo incomprensible), exige ser puesta en una historia para salir así de su oscuridad y acercarse a otro capaz de recibirla.

Primo Levi no sólo contó su historia (Si esto es un hombre) sino que acogió al interior de ella misma las historias de sus compañeros que presumía morirían sin poder contarlas. Ejemplo entre muchos, la historia de Ferrari: "Era, por consiguiente, un individuo especial: y me lo confirmó su historia, que me contó de muy buena gana y que recojo aquí" (310). Ese acto de "recoger”, más que un gesto de generosidad de Levi, apunta a la imperiosa necesidad de narrar para que nada quede en el olvido. Más aún, recoger las otras historias en la de él es de una u otra forma reconocer que su propia historia está entretejida con la de otros. Como cuando escoge como método el contar historias para mostrar las posibilidades de sobrevivencia: "En cuantos modos es posible acceder a la salvación, procuraré demostrarlo contando las historias de Schepschel, Alfred L., Elías y Henri” (123). El “contar historias” se constituye en una estructura subyacente a toda la obra de Levi, por un lado, y por otro es también una estructura vital, en la medida en que su labor principal es la de escritor. Ahora bien, cuando las historias de los compañeros desbordan cierta coherencia o estructura interna de su propio relato, aun así, Levi no las desecha, sino que las recoge posteriormente en sus cuentos o relatos. A modo de ejemplo de este frecuente proceder tenemos los relatos "El regreso de Cesare" y "El regreso de Lorenzo" en Lilít y otros relatos (1998), tomo en el que no se hace distinción alguna entre cuentos propiamente tales y este "contar historias".

Hay, de entre todas las historias que Levi narra en Si esto es un hombre, una que cobra vital importancia para lo que venimos diciendo. Los postulados, aunque desperdigados y en sí no teorizados de Levi en relación a la narración, se pueden resumir en lo siguiente: el acto de narrar no es solamente intrínsecamente humano, sino que además es, gracias a él, que advenimos como humanos en cuanto tales. Es decir, gracias a la palabra conservamos nuestra humanidad. Esto es al menos lo que se desprende del relato titulado "El canto de Ulises". Uno de los presos, apodado Pikolo, le pide a Levi que le enseñe italiano. Levi accede y logrando escapar a la vigilancia se da a la tarea de traducir algunos versos memorizados de La Divina Comedia de Dante. Importa aquí la experiencia que hace Levi producto de este narrar a otro e intentar simultáneamente una traducción: "Cuantas otras cosas habría que decir, y el sol ya está alto, pronto será mediodía. Tengo prisa, una prisa furibunda. Mira, atento Pikolo, abre los oídos y la mente, necesito que entiendas: 'Considerad', seguí, 'vuestra ascendencia: para vida animal no habéis nacido, sino para adquirir virtud y ciencia”” (146). Y aquí viene la "experiencia” de Levi: “Como si yo lo sintiese también por primera vez: como

\footnotetext{
Revista Iberoamericana, Vol. LXXVII, Núms. 236-237, Julio-Diciembre 2011, 771-788
ISSN 2154-4794 (Electrónico)
} 
un toque de clarín, como la voz de Dios. Por un momento, he olvidado quién soy y dónde estoy” (146). Esta súbita conciencia que le permite superar momentáneamente su estado de preso en un campo de exterminio y recordarle que por sobre todo es un hombre acontece precisamente en el marco del contar historias. Levi le cuenta a Pikolo un trozo de La Divina Comedia y es este contar a otro el que gatilla la lucidez y el autoconocimiento. Ahora bien, Levi aspira inmediatamente a transmitirle este segundo mensaje a su compañero de sufrimiento:

Pikolo me pide que lo repita. Qué buena persona es Pikolo, se ha dado cuenta de que me está haciendo el bien. O quizás se trata de algo más: quizás, a pesar de la traducción floja y el comentario pedestre y presuroso, ha recibido el mensaje, ha sentido que le atañe a todos los hombres en apuros, y a nosotros en especial; y que nos atañe a nosotros dos, que osamos hablar de estas cosas con los palos de sopa en los hombros. (146)

Es inserto en el acto de la narración-traducción que Levi tiene una experiencia reveladora sobre su condición de hombre y como ser social que rebalsa la experiencia personal y accede a un nosotros. "Nosotros" en primera instancia se refiere a Levi y Pikolo, pero luego se extiende metonímicamente a un plural que trasciende a los dos involucrados. La narración se vuelve así urgente, imprescindible y vital:

Detengo a Pikolo, es absolutamente urgente, que escuche, que comprenda [...] antes de que sea demasiado tarde, mañana él o yo podemos estar muertos, o no volver a vernos, debo hablarle, explicarle [...] de algo gigantesco que yo mismo sólo he visto ahora, en la intuición de un instante, tal vez el porqué de nuestro destino, de nuestro estar hoy aquí. (147)

Primo Levi no sólo “acoge”, como ya decíamos, las historias de otros para hacerlas suyas, sino que incorpora una historia del mundo literario-ficticio a su mundo con el resultado de que la incorporación, inserto en el encuentro entre dos presos, adviene en una experiencia común de liberación y de humanidad.

Si no hay narración y sobre todo si no hay quién la acoja, el mundo se vuelve pesadilla insostenible. De hecho, la posibilidad de no ser escuchado se convierte en pesadilla recurrente. Levi sueña una y otra vez que vuelve a su hogar y que narra su paso por el campo de concentración:

Es un placer intenso, físico, inexpresable, el de estar en mi casa, entre personas amigas, tener tantas cosas que contar: pero no puedo dejar de darme cuenta de que mis oyentes no me siguen. O más bien, se muestran completamente indiferentes: hablan confusamente entre sí de otras cosas, como si yo no estuviese allí. Mi hermana me mira. Se pone de pie sin decir palabra. (87)

$\begin{array}{lllll}\text { ISSN 0034-9631 (Impreso) } & \text { ISSN 2154-4794 (Electrónico) }\end{array}$ 
Esta situación de no ser escuchado provoca en Levi un dolor extremo: "Entonces nace en mí un dolor desolado, como ciertos dolores que apenas se recuerdan de los primeros años de la infancia: es el dolor en estado puro" (87). Levi comparte con otros compañeros su sueño recurrente y, para asombro, descubre que los demás viven similar pesadilla. Llegamos así a lo esencial de la narración: no sólo se debe y se puede contar, sino que toda narración demanda ser escuchada. De no ser así, la humanidad se vuelve una pesadilla, ausencia total de solidaridad y de transmisión de experiencias que permitan elaborar un nosotros.

Mediante el recorrido por los postulados de Ricoeur, White, Arendt y Levi, abordamos la pregunta por la narración más allá de una mera descripción de sus rasgos. La narración se eleva a categoría de conocimiento y es el medio mediante el cual el ser humano se constituye en cuanto tal. Llama la atención que todos los teóricos tratados ligan la actividad de la narración a la del sentido. Un mundo sin narraciones es un mundo opaco. Narrar es explicar, poner en orden, moralizar, subsistencia del sujeto, comunicación y actividad. Así, este recorrido nos permite una comprensión del sujeto y de su devenir histórico íntimamente ligado al acto de narrar.

\section{BiBLIOGRAFÍA}

Arendt, Hannah. La condición humana. Barcelona: Paidós, 2001.

Levi, Primo. Si esto es un hombre. Trilogía de Auschwitz: si esto es un hombre. La tregua, los hundidos y los salvados. Pilar Gómez Bedate, trad. Antonio Muñoz Molina, pról. Barcelona: El Aleph, 2005. 31-245.

Lilít y otros relatos. Barcelona: Muchnik, 1998.

Muñoz Molina, Antonio. Prológo. Trilogía de Auschwitz: si esto es un hombre. La tregua, los hundidos y los salvados. Barcelona: El Aleph, 2005. 9-21.

Ricoeur, Paul. Historia y narratividad. Barcelona: Paidós, 1999. Sí mismo como otro. Madrid: Siglo XXI, 1996.

Tiempo y narración. Vols. I, II y III. México: Siglo XXI, 2004.

White, Hayden. El contenido de la forma. Barcelona: Paidós, 1992. El texto histórico como artefacto literario. Barcelona: Paidós, 2003. 